\title{
A GESTÃO ESCOLAR NO CONTEXTO DA PRIVATIZAÇÃO NA EDUCAÇÃO BÁSICA
}

\author{
LA GESTIÓN ESCOLAR DE LA CONTEXTO DE LA PRIVATIZACIÓN EN LA \\ EDUCACIÓN BÁSICA,
}

\author{
SCHOOL MANAGEMENT IN THE CONTEXT OF THE PRIVATIZATION OF BASIC \\ EDUCATION
}

Teise GARCIA ${ }^{1}$

RESUMO: O artigo problematiza a incidência de atores privados na gestão escolar em redes de ensino brasileiras. A partir de pesquisa interinstitucional que analisou tendências de privatização na educação básica brasileira para a década correspondente a 2005-2015 e do contato com dados provenientes de outros estudos, discute-se as possíveis consequências e "heranças" dos programas privados para a organização do trabalho na escola. Conclui-se provisoriamente ser o maior legado o recrudescimento da burocracia e a interdição de pautas democráticas, indicando-se, todavia, a necessidade de mais estudos a partir do interior da escola com foco na gestão sob a tutela do setor privado.

PALAVRAS-CHAVE: Privatização. Gestão escolar. Gerencialismo.

RESUMEN: El artículo problematiza la incidencia de actores privados en la gestión escolar en redes estatales de enseñanza brasileñas. A partir de investigación interinstitucional que analizó tendencias de privatización en la educación básica brasileña para la década correspondiente a 2005-2015 y del contacto con datos provenientes de otros estudios, se discute las posibles consecuencias y "herencias" de los programas privados para la organización del trabajo en la escuela. Se concluye provisionalmente que el mayor legado es el recrudecimiento de la burocracia y la interdicción de pautas democráticas, indicándose, sin embargo, la necesidad de más estudios desde el interior de la escuela con foco en la gestión bajo la tutela del sector privado.

PALABRAS CLAVE: Privatización. Gestión escolar. Gerencialismo.

\footnotetext{
${ }^{1}$ Universidade de São Paulo (USP), Ribeirão Preto - SP - Brasil. Departamento de Educação, Informação e Comunicação. Tem experiência na área de Educação, com ênfase em Administração Educacional e Administração de Unidades Educativas na Educação Básica, desenvolvendo pesquisas sobre a gestão educacional no contexto das relações entre o público e privado. Coordena Seção Grupo de Estudos e Pesquisas em Política Educacional, Greppe-USP/RP. É vice-diretora estadual da Anpae (2017-2019), integra a Fineduca e é associada da Anped. Coordena o Programa de Pós-Graduação em Educação da FFCLRP (2017-2019). ORCID: <https://orcid.org/0000-0003-4351-3159>. E-mail: teiseg2@gmail.com
} 
ABSTRACT: The article problematiza the incidence of private actors in the pertaining to school management in Brazilian system of education.Based on an interinstitutional study that analyzed trends of privatization in Brazilian basic education for the decade corresponding to 2005-2015 and of the contact with data proceeding from other studies the possible consequences and "inheritance" of the private programs for the organization of work are discussed in school. It is provisionally concluded that the greatest legacy is the resurgence of bureaucracy and the banning of democratic guidelines, but there is a need for further studies from within the school, focusing on management under the private sector.

KEYWORDS: Privatization. School management. Managerialism.

\section{Introdução}

A privatização da educação escolar, tendência global reconhecida por ampla literatura internacional e nacional, concretiza-se em de formas divers, mas principalmente por meio da transferência de responsabilidades para o setor privado com subsidiamento público.

David Hill ao analisar os processo de privatização nos Estados Unidos e Grã-Bretanha afirma que os capitalistas têm para a escola:

1 - um Plano de Negócios para a Educação: este se concentra em, socialmente, produzir a força de trabalho (a capacidade das pessoas para trabalhar) para as empresas capitalistas; 2 - um Plano de Negócios na Educação: este se concentra em liberar as empresas para lucrar com a educação;3 - um Plano de Negócios para as Empresas Educacionais: este é um plano para as "Edubusinesses" (empresas educativas) inglesas e americanas lucrarem com as atividades internacionais de privatização. (HILL, 2003, p. 26)

Destaca-se a categorização dos três níveis de planos de negócio do capitalismo para a educação porque esta contribui a considerar, respeitadas as diferenças entre os contextos, a intervenção do setor privado sobre a educação da perspectiva de ampliação do capital, para além do interesse na resolução da chamada "crise fiscal", ou para arranjos de ideológicos. Tal como já registramos em outra ocasião, interessa especialmente também neste trabalho a terceira indicação de Hill, pois a gestão privada das políticas públicas em suas várias manifestações parece corresponder a esta perspectiva (ADRIÃO; GARCIA, 2014).

A gestão escolar, no contexto da administração gerencial, é objeto de interesse de atores diversos que no interior da escola podem realizar seu "plano de negócios", posto que setor privado empresarial representa a "expertise" para a administração pública. Proliferam consultorias, institutos e fundações que prometem qualificar a educação por meio de 
intervenção sobre a gestão escolar. Esta intervenção pode ser sobre a formação de diretores e diretoras de escolas, mas pode também ser mais do que isso quando são introduzidas tecnologias, práticas e rotinas de gestão empresarial, em alguns casos com a presença dos proponentes privados nas unidades escolares, é o caso do Instituto Unibanco com o Projeto Jovem de Futuro (PERONI, 2010; MONTEIRO, 2014)

O artigo aborda a privatização da gestão educacional na Educação Básica, com foco na gestão escolar ${ }^{2}$. Em diálogo com dados obtidos em pesquisa nas redes estaduais de ensino brasileiras e produção acadêmica sobre a temática, objetiva-se problematizar a incidência de representantes do setor privado sobre a gestão da escola pública ${ }^{3}$ em sua etapa obrigatória. Questiona-se as decorrências de programas desenvolvidos com e pelo setor privado para a gestão na unidade escolar.

Tem-se como pressuposto inicial que o desenvolvimento de programas com instituições privadas visando a alteração da gestão escolar e ancorados em tecnologias empresariais de gestão estimulam o que Licínio Lima (2012) designou como hiperburocratização, referindo-se à adoção de modelos gerenciais de administração. Ao analisar a administração educacional na realidade portuguesa nas últimas duas décadas o autor observa que:

a administração pública de tipo empresarial é anunciada como paradigma reformador do Estado e das organizações públicas, colocando o "cliente" em primeiro lugar, substituindo as organizações públicas por empresa privadas e por fundações e organizações sociais de direito privado; as regras burocráticas seriam substituídas pela desregulação, a centralização pela descentralização, a hierarquia pela competição, o direito público pelo direito privado [...] Isso altera, na verdade, muitos dos pressupostos da análise weberiana, mas não, necessariamente, a presença de dimensões burocráticas (LIMA, 2012, p. 140-41)

Embora o estudo mencionado se refira à realidade portuguesa, a reflexão é importante para o que se pretende aqui discutir sobre os programas com "parceiros privados" na educação pública e para a proposição de planos de pesquisa com vistas ao estudo da gestão escolar no contexto da privatização.

\footnotetext{
2 Neste trabalho assume -se os termos gestão e administração referidos à escola enquanto sinônimos, em concordância com Vitor Paro (2010).

${ }^{3}$ A incidência de atores privados sobre a gestão das escolas públicas relaciona-se fundamentalmente com a disposição política do gestor público em introduzir tecnologias empresariais de gestão na administração pública.
} 
Licínio Lima, ainda, em publicação recente designa por privatização lato sensu processos que implicam a "introdução de teorias e de modos de gestão privada no interior das organizações públicas" (LIMA, 2018). O autor observa que não se trata de forma incompatível com que denomina como privatização stricto sensu, como o estímulo a criação de escolas de iniciativa privada; ambas as formas podem ser compatíveis. Destaca, todavia, a expansão da privatização lato sensu na política pública. (LIMA, 2018).

A privatização no campo educacional, assim, configura-se em processo complexo podendo se apresentar em modelos que diversos, mas não necessariamente excludentes. Para a gestão escolar, entende-se, também se apresenta como possibilidade a transferência da gestão para o setor privado por meio de delegação de todas as responsabilidades ou de parte delas, ou ainda pela adoção de instrumentos privados de gestão por parte do poder público.

Considerando estes aspectos, além desta introdução, o texto é organizado em três sessões: breves notas sobre os interesses e interessados na reforma da gestão pública; a gestão escolar em reforma pelo setor privado; e, ao final, com intenção de conclusões provisórias, apresentam-se algumas considerações sobre o tema.

\section{Administração gerencial e os interessados na gestão pública}

A reflexão sobre os interesses privados na gestão pública toma como ponto de partida que o contexto global é de reformas no âmbito dos estados nacionais ancoradas em modelos privados de gestão. A chamada Nova Gestão Pública, conjunto de medidas visando a reforma do estado a partir de padrões privados, apresenta-se como referência hegemônica em ambos os hemisférios do globo. No Brasil, a partir dos anos 1990, com a reforma do estado implementada pelo Ministério de Administração e Reforma do Estado, MARE, e continuada nas décadas seguintes (GARCIA; ADRIÃO; BORGHI, 2009), fortalece-se a presença da chamada sociedade civil nas proposições de modernização da administração pública. A ideia de governança ${ }^{4}$ toma fôlego e agentes privados comparecem organizadamente em movimentos na implementação de mudanças na gestão pública: são associações tradicionais, instituições confessionais, grupos empresariais muitos dos quais vinculados a fundo de

4) Michel Temer assinou, em 2017, decreto presidencial dispondo sobre a "política de governança da administração pública federal direta, autárquica e fundacional”, que entre outras determinações criou o Comitê Interministerial de Governança CIG, para assessorar a presidência da República. Dos grupos de trabalho que compõem o CIG podem participar instituições privadas. (BRASIL, 2017) 
investimentos e corporações de caráter transnacional, os chamados filantropos de risco, redes de empresários e fundações.

A adoção dos modos de gestão privada nas organizações públicas é compatível com a delegação da gestão a segmentos do setor privado que assumem a responsabilidade por programas e projetos. Tal é o caso do Movimento Brasil Competitivo, MBC. O movimento é uma Organização da Sociedade Civil de Interesse Público, OSCIP, que atua junto aos governos federal, estaduais e municipais por meio de contratação e estabelecimento de convênios, com objetivo declarado de contribuir para o aumento da competitividade nacional, perspectiva sob a qual $\mathrm{MBC}$, embora não tenha se originado com missão no campo educacional, mantém em seu portfólio registro de atuações juntos a secretarias estaduais de educação em seis estados da federação e no Distrito Federal. ${ }^{5}$

No campo da gestão educacional atuam Institutos e Fundações vinculados a grandes grupos empresariais e instituições financeiras, tais como Instituto Unibanco, Instituto Natura, Instituto Ayrton Senna, Fundação Lemann, Fundação Educar DPaschoal, Parceiros da Educação, Instituto Itaú Social, Todos Pela Educação (este agrega diferentes movimentos) ${ }^{6}$ entre outros que, sem fins lucrativos, implementam programas que incidem sobre conteúdo da educação pública, no âmbito pedagógico e na gestão (PERONI; CAETANO, 2015).

Além dos grupos sem fins lucrativos que, representando o segmento empresarial, atuam no campo da gestão pública e educação, proliferam instituições privadas o com fins lucrativos que encontram na gestão pública fonte importante de ganhos. No Brasil, importante exemplo é a Falconi Consultoria de Resultados, originária da Fundação Cristiano Otonni, FCO, em Minas Gerais.

A FCO, nos anos 1990, introduziu de forma pioneira os pressupostos da "gestão de qualidade total" na gestão pública no estado de Minas Gerais. Em 2003, a fundação se transforma no Instituto de Desenvolvimento Gerencial, Indig, com atuação sem fins lucrativos. O Indig desenvolveu programas na educação pública em vários estados brasileiros. Em 2012, o instituto de transforma na FALCONI Consultores de Resultado, empresa de

\footnotetext{
5 O MBC foi fundado por Jorge Gerdau Johannpeter em 2001. Em 2018 é presidido por Cláudio Leite Gastal. De seu Conselho Superior fazem part e cinco representantes da administração pública. Em 2011 o governo federal cria a Câmara de Políticas de Gestão e Competitividade, CGDC, com a qual o MBC desenvolveu parcerias. Em 2014 foi noticiado o "abandono da Câmara pelo governo e a insatisfação dos empresários com suas atividades (O ESTADO DE SÃO PAULO, 2014)

6 Maiores informações sobre programas podem ser encontradas nas páginas oficiais das entidades: https://institutoayrtonsenna.org.br/pt-br.html; http://www.institutonatura.org.br/; https://www.institutounibanco.org.br; https://www.itausocial.org.br/; $\quad$ www.todospelaeducacao.org.br; http://www.educardpaschoal.org.br/; https://fundacaolemann.org.br .
} 
capital fechado que mantém a assessoria à administração pública (FALCONI; ARRUDA; NÓBREGA, 2013). A consultoria criou, em 2015, uma divisão de Educação destinada a atender escolas públicas e privadas na implantação da gestão de resultados. A divisão foi lançada em evento, no qual, segundo a revista Valor, economistas e acadêmicos defenderam privatização da educação pública por meio de parcerias com o setor privado (VALOR, 2015).

Encerrando estas breves notas sobre a privatização contexto da Nova Gestão Pública, retoma-se observação feita em 2009:

Descentralizar e privatizar-submetendo a esfera estatal aos controles do mercado ou que simulem mercados-são palavras de ordem que se encontram concatenadas. A busca por uma maior eficiência; a ampliação de novos mercados para a reprodução do capital;a tentativa de minimizar a vulnerabilidade das democracias [ vulnerabilidade para o mercado]; estas são algumas possíveis respostas para a atual reconfiguração das relações público-privado (GARCIA, ADRIÃO, BORGHI,2OO9,p.24)

\section{A gestão escolar "em reforma": atores privados e programas em redes públicas de ensino}

A partir de dados obtidos pela pesquisa interinstitucional Mapeamento das estratégias de privatização da Educação Básica no Brasil - $(2005-2015)^{7}$, sistematiza-se informações sobre a incidência de atores privados na gestão educacional em redes estaduais de ensino, analisando-se três programas com foco na gestão escolar.

O mapeamento sobre todas as redes estaduais de ensino e do Distrito Federal, concentrou-se na coleta de dados relativos às estratégias de privatização na primeira década de vigência da Lei de Responsabilidade Fiscal $^{8}$. A pesquisa foi realizada em páginas oficiais das secretarias de educação, com recurso também a busca controlada na plataforma google a partir de descritores previamente definidos. ${ }^{9}$

\footnotetext{
${ }^{7}$ A pesquisa da qual participei, coordenada Theresa Adrião, realizou-se com apoio do CNPq e Fapesp no âmbito do Grupo de Estudos e Pesquisas em Políticas Educacionais, GREPPE composto por pesquisadoras vinculadas às três universidades públicas paulistas (Unesp, Unicamp e Usp) e UFRJ.

${ }^{8}$ A Lei Complementar 101, de 2000, teve seu prazo limite para implementação em 2005.

9 Para consulta ao mapeamento acessar https://www.greppe.fe.unicamp.br/ptbr/mapeamento_da_insercao_do_setor_privado_nas_redes_estaduais_de_educacao_2005_2015

Para maior detalhamento em relação à metodologia de pesquisa, consultar no mesmo endereço a aba"Notas Metodológicas".
} 
As estratégias de privatização da educação foram consideradas em três dimensões: oferta, currículo e gestão educacional ${ }^{10}$ (ADRIÃO, 2015). Programas e projetos desenvolvidos nas redes públicas de ensino com a presença de atores privados foram alocados em cada uma das dimensões de acordo com seus objetivos declarados. A dimensão gestão educacional $^{11}$ apreendeu: sistemas de avaliação e bonificação por produtividade a trabalhadores da educação, contratação de assessorias e transferência da gestão para instituições privadas.

$\mathrm{O}$ artigo ora apresentado se limita à reflexão centrada nos programas e projetos com participação do setor privado, desenvolvidos por meio de assessorias à gestão pública. ${ }^{12}$

Em todo o território nacional foram localizados 85 programas voltados à gestão educacional no período, com 154 atuações de instituições privadas com fins lucrativos imediatos e sem fins lucrativos, caso dos Institutos, Fundações, agências financeiras internacionais, Organizações da Sociedade Civil de Interesse Público, agências internacionais, Organizações Sociais, sindicatos patronais, consultorias especializadas, dentre outras designações. ${ }^{13}$

A maior parte dos atores privados atuando sobre a gestão educacional se concentra nas regiões Sudeste e Nordeste, 81 e 38 instituições respectivamente. No limite oposto encontrase a região Norte, na qual foram localizadas oito instituições privadas para o período selecionado, atuando no estado do Pará e Amazonas, únicos da região nos quais foi registrada a presença de atores privados na gestão educacional. A região Centro-Oeste registrou 13 instituições privadas e a região Sul, 11. (ADRIÃO coord., 2018). A tabela 1 informa sinteticamente o número de programas e atores privados por estado e região.

${ }^{10}$ Há possibilidade de se encontrar no âmbito desta dimensão programas mais concentrados no âmbito da unidade escolar, programas referentes às secretarias de educação e programas que atuam nas duas esferas.

${ }^{11} \mathrm{O}$ termo apreende ações desenvolvidas no âmbito da unidade escolar e secretaria de educação

${ }^{12}$ Convêm observar que a maioria dos programas em território nacional para o período selecionado encontra-se na dimensão currículo, representando 64,3\% dentre o total de 384 programas. A dimensão gestão é o foco em $22,3 \%$ dos casos e o subsídio a oferta educacional, por fim, corresponde a 14,6\%.(ADRIÃO, coord.2018).

${ }^{13}$ A pesquisa trabalhou com as denominações auto atribuídas. (ADRIÃO, 2018). 
Tabela 1- Programas em gestão educacional desenvolvidos em redes estaduais de ensino com atores privados (2005-2015): número de frequência de instituições

\begin{tabular}{llcc}
\hline Região & $\begin{array}{c}\mathbf{N}^{\circ} \text { de Programas } \\
\text { identificados }\end{array}$ & $\begin{array}{c}\text { Atores privados por } \\
\text { estado/região geográfica }\end{array}$ \\
\hline \multirow{2}{*}{ e } & Norte & 10 & 8 \\
& Nordest & 27 & 38 \\
& Centro & 13 & 15 \\
& Sudeste & 26 & 81 \\
& Sul & 9 & 12 \\
Brasil & Total & $\mathbf{8 5}$ & $\mathbf{1 5 4}$ \\
\hline
\end{tabular}

Fonte: A autora a partir de Adrião (coord). Mapeamento das estratégias de privatização da educação básica no Brasil (2005-2015). 2018/Cnpq-Fapesp.

Destacam-se, dentre o conjunto dos atores privados localizados no período, três Institutos com presença significativa no país. São eles: Instituto Unibanco, responsável pelo Programa Jovem de Futuro, com atuação em todas as regiões geográficas brasileiras; Instituto Ayrton Senna que desenvolveu, dentre outros projetos, o Programa Gestão Nota 10 em redes estaduais; e o Instituto de Corresponsabilidade pela Educação, ICE, que dissemina o Programa Escola da Escolha ${ }^{14}$. (ADRIÃO, 2018).

Para o objetivo deste trabalho, qual seja, problematizar as decorrências sobre a gestão escolar dos programas com atores privados, sobretudo com interrogações sobre o que de fato seria alterado com as proposições de tais atores, será feito exercício de apresentação, comparação e reflexão, sobre concepção de gestão escolar e papel do diretor escolar que os três institutos apresentam em seus principais programas. Apresenta-se a seguir, ainda que brevemente, os três institutos. ${ }^{15}$

O Instituto Unibanco foi criado em 1982 para realizar os investimentos sociais do Unibanco. No final dos anos 1980 e anos 1990 atuava em educação promovendo cursos sobre empreendedorismo e programas de alfabetização. É em 2003 que o IU passa a apresentar propostas para a educação formal e em 2007, já declarando intencionalidade de atuar em políticas públicas, institui o Projeto Jovem de Futuro iniciado em três escolas na cidade de São Paulo. A expansão se deu com a implantação do programa em escolas das redes estaduais de Minas Gerais e Rio Grande do Sul e, em 2009, em mais unidades próprio estado de São Paulo. Em 2011, o IU firma parceria com a Secretaria de Assuntos Estratégicos da

${ }^{14}$ O Programa originalmente era denominado "Modelo Escolas em Tempo Integral”. Nas redes estaduais e municipais onde é implantado recebe diferentes designações.

15 A expressão programa é utilizada compreendendo-se como significando um conjunto de ações ordenadas a partir de definições de prazos, procedimentos e recursos financeiros necessário. (ADRIÃO; GARCIA, 2015) . 
Presidência, SAE, órgão executivo federal com status de ministério e com as secretarias de educação dos estados de Ceará, Goiás, Mato Grosso do Sul, Pará e no Piauí para implantar o Jovem de Futuro como política associada ao Programa Ensino Médio Inovador, promovido pela SAE. A parceria com a SAE, firmada por meio de Termos de Cooperação Técnica envolve também desenvolvimento de pesquisas avaliações (PERONI; CAETANO, 2015, RODRIGUES, 2016; BALDUÍNO, 2016, entre outros).

O Instituto de Corresponsabilidade pela Educação foi criado no início dos anos 2000 pelo executivo Marco Magalhães e um grupo de apoiadores com o objetivo de promover, em associação ao governo estadual de Pernambuco, a revitalização de tradicional escola pública estadual em Recife, capital do estado. Fez parte do processo a inovação pedagógica com a proposição de extensão do ensino médio para período integral sob modelo de gestão diferenciado. O ICE, durante anos, disseminou o modelo para secretarias de educação com foco no Ensino Médio. Posteriormente introduziu-se o modelo para as séries finais do ensino fundamental e mais recentemente, segundo o instituto, também para as séries iniciais do EF (ICE-LIVRETO DIGITAL, s/d).

O Instituto Ayrton Senna, criado em 1994, iniciou suas atividades na educação formal, educação complementar e educação e tecnologia, sempre na perspectiva de atuar sobre as políticas públicas educacionais, desenvolvendo projetos e pesquisas. Em 2002 lança o Programa Gestão Nota 10, dirigido a gestores educacionais para os quais oferece formação e ferramentas gerenciais de gestão. (INSTITUTO AYRTON SENNA 2014, PERONI; ADRIÃO, 2010; PINHEIRO, 2010). Em janeiro de 2016,o Instituto estabeleceu parceria com a CAPES para Programa de Apoio à Formação de Profissionais no Campo das Competências Socioemocionais.

Os três institutos e programas foram objetos de pesquisas individuais e coletivas (alocadas em uma única instituição de pesquisa ou de caráter interinstitucional), em todo o território nacional que possibilitam visão minuciosa sobre: atores privados; implementação dos programas, financiamento, além de análises importantes que contextualizam a ação privada empresarial no contexto das reformas de estados nacionais e das redes de ensino. Não se pretende aqui, portanto, retomar esses aspectos ou detalhar as trajetórias de cada um dos programas e instituições, as articulações entre estes e relações com o poder executivo, ou ainda as redes de atores privados. Pretende-se exclusivamente retomar a problematização 
sobre as proposições para a gestão escolar, também já objeto de outras pesquisas, sobretudo em relação à pretensa permanência dos modelos propostos nas unidades escolares ${ }^{16}$.

Os programas em foco têm em comum entre outros aspectos, estruturarem-se d de modo a manter, em fases iniciais, representantes em relação mais direta com os gestores educacionais, o que não impede que sejam anunciadas pelos institutos redes de formação e manutenção de algumas formas de apoio às secretarias educacionais após a implementação. Os institutos se comportam como "implantadores" de reformas educacionais que pretendem alcançar a gestão das unidades escolares, valendo-se de diferentes estratégias: formação, produção de instrumentos de controle e avaliação do trabalho, monitoramento da gestão e veiculação de materiais de divulgação. Em comum também têm o fato de fazer constar em seus materiais visão da gestão escolar, método, instrumentos de apoio e controle do trabalho e formas de avaliação de desempenho das escolas. Nos limites deste trabalho nos concentramos na concepção de gestão, método e visão sobre o papel do diretor escolar, reconhecendo que há também peculiaridades em cada uma das propostas.

As informações sobre as concepções de gestão escolar e método adotados pelos três institutos foram retiradas de suas páginas oficiais e documentos produzidos, assim como as informações relativas aos objetivos do programas, método e atuação do gestor. Neste último quesito, excetua-se a informação sobre o IAS, que foi obtida em fonte secundária (COMERLATTO, 2013). A autora sintetiza em seu trabalho documento utilizado pelo Instituto nas redes públicas e não disponível em sua página oficial.

O ICE possui publicações próprias às formações oferecidas a gestores. Os materiais mais recentes, produzidos como o apoio do Instituto Natura, referem-se ao modelo pedagógico e ao modelo de gestão, do qual foram extraídas as informações relativas ao método de gestão e ao papel do diretor escolar. A concepção mais geral de gestão escolar foi buscada na página oficial do instituto. ${ }^{17}$

\footnotetext{
${ }^{16}$ Sem a pretensão de produzir extenso inventário e com o risco de não abarcar produções relevantes sugere-se, para maior aprofundamento no campo da privatização da educação básica, a leitura pesquisas que se dedicaram estudar os Institutos e Programas em foco. (ADRIÃO; PERONI, 2013, 2011, RODRIGUES, 2016, BALDUÍNO, 2016, COMERLATTO; CAETANO, 2016, LUMERTZ, 2008, ADRIÃO; GARCIA, 2014; SILVA, 2012, entre outros)

${ }^{17} \mathrm{O}$ documento digital "Tecnologia de Gestão Educacional: princípios e conceitos (ICE, 2015) é o utilizado neste texto. Anteriormente, o ICE havia produzido o documento "Manual Operacional: Modelo de Gestão Tecnologia Empresarial Socioeducacional (TESE) - Uma nova escola para a juventude brasileira-Escolas de Ensino Médio em Tempo Integral" Embora a tecnologia de gestão seja apresentada com diferentes nomenclaturas nos documentos, os referenciais permanecem ancorados Tecnologia Empresarial Odebrecht
} 
O Instituto Unibanco, IU, apresenta a proposta do Circuito de Gestão em sua página oficial e em documentos de acesso a gestores que participam das formações oferecidas e em seus relatórios de atividades. Neste texto, recorreu-se à página oficial do Programa Jovem de Futuro, Circuito de Gestão e o Relatório de Resultados de 2012.

O Instituto Ayrton Senna, finalmente, desenvolve diversos programas, dentre eles o Programa Gestão Nota 10. Mais recentemente, como informa o próprio IAS, o programa deixou de ter existência em separado de outras iniciativas. Recorreu-se à página da Rede Vencer e dois documentos produzidos pelo instituto: "Formação-Foco IAS 2011" e "Instituto Ayrton Senna-Relatório de Resultados 2012”, ambos acessados por meio digital.

Os documentos e páginas oficiais mencionados contém informações importantes sobre os programas, dentre as quais selecionou-se àquelas relativas à gestão escolar e o papel do diretor na unidade de ensino, posto que os três programas se ocupam da formação de gestores, desde os órgãos centrais até a unidade escolar.

A concepção de gestão não é definida a partir de referenciais do campo educacional e nem é explicitada com igual clareza: o PJF e o Gestão Nota 10 têm documentos que indicam o foco em resultados. Para o PJF o modelo de gestão tem nome: é Gestão Escolar para Resultados, GEPR. Este é também no nome do curso para gestores que o instituto realiza quando atua em escolas que integram o programa. A página informa que o modelo "visa contribuir para rotinas da gestão escolar" e se materializa pelo método Circuito de Gestão (PORTAL, INSTITUTO UNIBANCO, s.d).

O Programa Gestão Nota 10 apresenta a gestão escolar como "articulação de conhecimentos e de recursos humanos, materiais e financeiros com foco em resultados" (FOCO IAS, 2011, p. 2). Já nos documentos do ICE é possível localizar com maior clareza que a gestão escolar não porta diferenciais relevantes em relação à gestão empresarial, sendo, portanto, a experiência gerencial empresarial o ponto de partida para seu desenvolvimento (ICE, s.d).

As informações obtidas nas várias fontes consultadas foram ordenadas no Quadro 1 em três eixos: objetivos do programa; gestão da escola; método de gestão; diretor da escola. 
Quadro 1 - Ator privado, Programa, objetivos, método de gestão e papel do diretor escolar

\begin{tabular}{|c|c|c|c|}
\hline & $\begin{array}{l}\text { Instituto Ayrton } \\
\text { Senna }\end{array}$ & $\begin{array}{c}\text { Instituto de } \\
\text { Corresponsabilidade em } \\
\text { Educação }\end{array}$ & Instituto Unibanco \\
\hline Programa & Gestão Nota 10 & Escola da Escolha & Jovem de Futuro-PJF \\
\hline Objetivos & $\begin{array}{l}\text { "Gerenciamento das rotinas nas } \\
\text { escolas e secretarias para } \\
\text { melhoria da qualidade do } \\
\text { ensino. O sucesso educacional é } \\
\text { uma questão gerencial e baseia- } \\
\text { se em estratégias de } \\
\text { acompanhamento do processo } \\
\text { de aprendizagem." (IAS, } \\
\text { RELATÓRIO r DE } \\
\text { RESULTADOS 2012,p.28) }\end{array}$ & $\begin{array}{l}\text { "Formação de um jovem que ao } \\
\text { final da educação básica deverá ter } \\
\text { formulado um Projeto de Vida } \\
\text { como sendo a expressão da visão } \\
\text { que ele constrói de si e para si em } \\
\text { relação ao seu futuro e define os } \\
\text { caminhos que perseguirá para } \\
\text { realizá-la em curto, médio e longo } \\
\text { prazo."(ICE, 2015a, p.28) }\end{array}$ & $\begin{array}{l}\text { [...]estruturado com base na } \\
\text { premissa de que uma gestão de } \\
\text { qualidade, eficiente, participativa e } \\
\text { orientada para resultados, com } \\
\text { equidade, pode proporcionar } \\
\text { impacto significativo no } \\
\text { aprendizado dos estudantes. } \\
\text { (PORTAL, } \\
\text { UNIBANCO, s.d) }\end{array}$ \\
\hline $\begin{array}{l}\text { Método } \\
\text { de Gestão }\end{array}$ & $\begin{array}{l}\text { [...] estabelecimento do ciclo } \\
\text { que pode ser chamado de } \\
\text { virtuoso: diagnóstico } \\
\text { situacional; planejamento; } \\
\text { execução acompanhamento e } \\
\text { avaliação; novo diagnóstico } \\
\text { replanejamento resultados" } \\
\text { (FOCO IAS, 2011, p.3, grifos } \\
\text { meus) }\end{array}$ & $\begin{array}{l}\begin{array}{l}\text { "Tecnologia } \\
\text { Educacional }\end{array} \text { Gestão } \\
\text { Princípios: Ciclo Virtuoso, } \\
\text { Educação para o Trabalho, } \\
\text { Comunicação } \\
\text { Conceitos:Descentralização, } \\
\text { Delegação Planejada, Ciclo PDCA } \\
\text { O Ciclo PDCA (Plan, Do, Check, } \\
\text { Act) é um conceito e um } \\
\text { instrumento destinado a apoiar o } \\
\text { processo de melhoria contínua que } \\
\text { considera as fases: planejar, } \\
\text { executar, avaliar e ajustar." (ICE, } \\
\text { 2015b, p.16) }\end{array}$ & $\begin{array}{l}\text { "O Circuito de Gestão é o método } \\
\text { que concretiza a Gestão Escolar } \\
\text { para Resultados de Aprendizagem } \\
\begin{array}{l}\text { (GEpR) [...] Esse método foi } \\
\text { inspirado }\end{array} \text { no } \\
\text { (plan, do, check, act), que em } \\
\text { português significa planejar, } \\
\text { executar, checar e atuar/ajustar." } \\
\text { (PORTAL, } \\
\text { UNIBANCO -MÉTODO, s.d) }\end{array}$ \\
\hline $\begin{array}{l}\text { Diretor } \\
\text { Escola }\end{array}$ & $\begin{array}{l}\text { Garantir a implementação da } \\
\text { política educacional definida } \\
\text { pela Secretaria de Educação. } \\
\text { Implementar as autonomias(...)e } \\
\text { a gestão financeira na escola, } \\
\text { Responsabilizar-se pelos } \\
\text { resultados da escola. Coletar, } \\
\text { analisar e consolidar os dados } \\
\text { referentes ao funcionamento da } \\
\text { escola e repassá-los ao } \\
\text { superintendente escolar. } \\
\text { Acompanhar e avaliar a atuação } \\
\text { e o resultado do trabalho. } \\
\text { Liderar os membros da } \\
\text { comunidade escolar no alcance } \\
\text { das metas da escola [...] (IAS, } \\
\text { In COMERLATTO, 2013, p. } \\
\text { 134) }\end{array}$ & $\begin{array}{l}\text { O Gestor tem } \begin{array}{r}\text { como } \\
\text { principal }\end{array} \\
\text { responsabilidade } \\
\text { coordenar as diferentes áreas da } \\
\text { escola, integrar os resultados } \\
\text { gerados por todos e educar sua } \\
\text { equipe pelo exemplo e trabalho, } \\
\text { inspirando-a na continuidade do } \\
\text { projeto escolar (ICE, 2015, p.6) }\end{array}$ & $\begin{array}{l}\text { Cabe ao gestor liderar processos } \\
\text { dentro da escola, envolver a } \\
\text { comunidade escolar no decorrer da } \\
\text { implementação do circuito[de } \\
\text { gestão], disseminar informações, } \\
\text { motivar professores e estudantes, } \\
\text { propor reflexões e buscar caminhos } \\
\text { para os desafios enfrentados pela } \\
\text { escola para o avanço da } \\
\text { aprendizagem. } \\
\text { (PORTAL, INSTITUTO } \\
\text { UNIBANCO -MÉTODO, s.d) }\end{array}$ \\
\hline
\end{tabular}

Fonte: Elaboração da autora a partir do Portal do Instituto Unibanco; Comelatto (2013); ICE (2015; FOCOS-IAS (2011).

A gestão como forma de se assegurar uma dada qualidade integra a apresentação dos objetivos em todos os programas. Os programas Escolha de Escola e PJF destacam a formação do jovem como objetivo final. O instituto Unibanco indica o papel da gestão 
escolar no alcance da formação proposta. Já no Programa Gestão Nota 10 o objetivo é claramente apresentado o gerenciamento das rotinas escolares.

O item "método de gestão", todavia, é o que deixa mais clara a visão dos programas sobre a gestão escolar: o ciclo Plan, Do, Check, Act, PDCA é mencionado em documentos dos três programas.

O ciclo PDCA origina-se no desenvolvimento da Gestão de Qualidade Total, GQT, tecnologia de gestão com incidência inicial sobre o controle da produção no chão da fábrica, desenvolvendo -se para uma tecnologia com perspectiva de aprimoramento da organização como um todo. A GQT tem suas origens nos estudos sobre controle de processo desenvolvidos estatístico estadunidense Walter Shewart, ainda década de 1930( TEIXEIRA, 2006). A partir da década de 1950, o controle é introduzido no Japão, com a contribuição de W. Edwards Deming e Joseph Juran. Deming se tornou estudioso e disseminador da gestão de qualidade total. Este autor é citado com frequência nas obras que trazem os princípios da GQT e o Ciclo PDCA para a educação, tais como os trabalhos de Cosete Ramos nos anos 1990.

Deming propõe o controle do processo de trabalho sob 14 princípios $^{18}$ e é disseminador importante da estratégia Ciclo PDCA em muitos países. O foco do Ciclo é o melhor controle do processo de produção e organização do trabalho nas quatros fases que originam a sigla: planejar, executar, avaliar e ajustar. (PINHEIRO, 2010; SILVA, 2012).

A difusão desta tecnologia de gestão no campo educacional deve muito a Vicente Falconi Ramos ${ }^{19}$ nos anos 1990, quando a Fundação Christiano Otonni, sob sua direção, implementou a Gestão de Qualidade Total na educação escolar mineira, em experiência pioneira (OLIVEIRA; DUARTE 1997; OLIVEIRA 1997; ADRIÃO; PERONI 2010, entre outros). A adoção do Ciclo PDCA é apresentada como a solução qualificar o processo de trabalho na escola. O diretor, nessas proposições, é liderança máxima, responsável pelo alcance de metas.

18 Os princípios são: Filosofia da qualidade; Constância de propósitos; Avaliação no processo; Transações em longo prazo; Melhoria constante; Treinamento em serviço; Liderança; Afastamento do medo; Eliminação de barreira; Comunicação produtiva; Abandono de cotas numéricas; Orgulho da execução; Educação e aperfeiçoamento e Ação para transformação (RAMOS, 1992, p. 12).

${ }^{19}$ Também dissemina a ideias Cosete Ramos que, nos anos 1990, publiciu obras como Excelência na Educação: a Escola de Qualidade Total, de 1992 e A Pedagogia da Qualidade Total, em 1994 
Os três programas mencionados não fazem alusão à gestão de qualidade total em seus documentos, mas utilizam a ferramenta que lhe é própria, tal como orienta a Falconi Consultoria de Resultados, conforme já mencionado neste texto.

A Gestão por Resultados, apresentada como inovação na administração escolar é, assim, reedição de estratégias empresariais que combinam, a despeito de inovações, o foco em metas estabelecidas de maneira monocrática, ao velho estilo burocrático, com o intenso cuidado no controle do trabalho alheio (BRAVERMAN, 1974). Deve-se considerar ainda a homogeneidade nas proposições para a gestão escolar: com variações sob outros aspectos, os atores privados entendem que só há um meio de o trabalho ser organizado na escola e somente um formato para a gestão escolar. Assim como os princípios para a administração geral formulados por Henry Fayol para a empresa capitalista na primeira metade do século XX inspiraram inúmeros educadores.

O papel diretor escolar por sua vez, apresentado como liderança fundamental ao sucesso dos programas, reedita a tradicional centralidade do administrador já referida por Vitor Paro $(2012,2010)$. O autor argumenta que a centralidade do diretor escolar na unidade de ensino não o exime de ocupar uma posição de preposto frente às chefias imediatas (PARO, 2012).

Pode-se inferir que, frente às proposições dos atores privados, os diretores escolares se veem em situação mais complexa do que a tradicional: lideranças e responsáveis últimos na implementação bem sucedida dos programas privados, os diretores escolares devem responder na unidade de ensino pelo seu sucesso frente ao órgão executivo imediatamente superior e também aos atores privados que controlam o processo de trabalho e acessam seus resultados por meios diversos tais como sistemas de informação, presença de técnicos no interior da escolar, produção de premiações, implantação de instrumentos de avaliação em pareceria com o poder público. ${ }^{20}$

É importante observar que se a gestão por resultados introduz estratégias mais recentes da administração empresarial, não se altera, além da centralidade do diretor escolar, o peso da técnica e do planejamento na gestão da educação, tal como nas reformas educacionais promovidas pela ditadura civil-militar (SOUZA; TAVARES, 2014).

${ }^{20}$ Nos limites deste texto não é possível mencionar cada uma das estratégias tais como: Sistema Instituto Ayrton Senna de Informação, do IAS; as avaliações realizadas por técnicos do PJF-IU que resultavam em transferência de recursos para a escola; a participação do ICE nos processos de seleção e avaliação de profissionais (orientação técnica e/ou presença de técnicos).Indica-se a leitura das pesquisas já referidas neste artigo. 
Ressalta-se o caráter de reedição presentes nestas estratégias, incorporadas a um modelo neotecnicista (FREITAS, 2012) de organização do trabalho na escola. A respeito das possíveis "novidades" trazidas pelo modelo privado, Luiz Carlos de Freitas já havia alertado que se trata de uma reedição:

Está de volta uma nova versão do tecnicismo descrito por Saviani (1983). A disputa pelo campo da organização do trabalho pedagógico da escola, feita com vigor por estas teorias requentadas, pode ser vista a olho nu no interior das escolas" (FREITAS, 2014, p. 1087)

As reflexões do autor propõem que consideremos o quão há de realmente de novo na gestão por resultados e nas tecnologias para sua implementação. Conforme já registrado neste texto, pesquisas que enfocam programas privados importantes (com expressão nacional) em escolas públicas, indicam haver uma forte tendência a que mais significativo seja para os profissionais o aumento do volume de trabalho relativo ao registro e controle, coerentemente ao que Licínio Lima denomina como hiperburocratização.

Como premissa vale o que diz o mercado: a gestão é fundamental no asseguramento da ampliação dos lucros, logo esta ideia é válida também para a escola, resultando em proposições que se concentram em estratégias de ampliação controle sobre o trabalho em relação ao já tradicionalmente estabelecido estímulo à competitividade. Sob esta premissa se ocultam as perspectivas de consecução dos planos de negócios (HILL, 2003) e também se revelam o desconhecimento sobre a natureza do trabalho pedagógico e a ausência uma compreensão mais rigorosa sobre administração (PARO, 2018)

Recorre-se ao conceito de administração tal como o desenvolve Vitor Henrique Paro, para o qual a administração em seu sentido geral corresponde a utilização racional de recursos para alcance de fins determinados (PARO,1988, 2012).Os fins são, portanto, determinantes na forma por meio da qual os elementos da administração , "coordenação do esforço humano coletivo" "e utilização racional de recursos” são assimilados. (PARO, 2012). Juntamente com o autor questiona-se os padrões de gestão propugnados pelos programas privados são eficientes para que o processo educativo escolar seja concluído com sucesso. Tomando-se por produto da educação a "atualização histórico-cultural" humana (PARO, 2012, 2010) questiona-se se o controle sobre o trabalho tal como o indicado, a restrição curricular ao que pode ser mensurável pela gestão, a exacerbação da burocracia são meios realmente administrativos para a realização da educação. 
Na sociedade capitalista, entretanto, a administração capitalista só existe pautada em uma racionalidade que serve aos interesses do capital, que são os de sua expansão e não ao ser humano genérico. (PARO, 2012), razão pela qual não ser estranho à administração escolar sua identificação com a administração empresarial ${ }^{21}$. Todavia, também se toma em consideração, a partir do conceito de administração enunciado, a ausência de coerência entre as formas tipicamente capitalistas de administração e o propósito educativo da educação escolar e, ainda, a potencialidade de as proposições penetraram de fato no cotidiano da gestão escolar.

O que de fato permanece na escola após a implementação de programas com a lógica privada $^{22}$ é incorporado às práticas de gestão com o relevante para a organização do trabalho? As tentativas de produzir alterações na gestão escolar, sobretudo na atuação do diretor escolar, trazem consequências para o trabalho desenvolvido na unidade?

Pesquisa coordenada por José Alberto Rosa Ribeiro, docente da UFRGS, “ouviu”, por meio de questionários profissionais vinculados a escolas estaduais em Minas Gerais e Rio Grande do Sul nas quais o Programa Jovem de Futuro foi implementado em sua fase piloto. Os questionários visaram apreender efeitos significativos registrados pelos profissionais com o programa. A fase inicial da pesquisa já detectara que o PJF não havia alcançado plenamente seus objetivos originais relativos à redução do abandono, elevação de desempenho dos estudantes em avaliações de larga escala nas disciplinas Português e Matemática, e redução de estudantes com rendimento abaixo do nível intermediário do SAEB. (RIBEIRO; GRABOWSKI; MARÇAL, 2017).

A aplicação dos questionários, por sua vez, captou como efeito mais importante do programa a disponibilidade de recursos (naquela fase o IU aportava recursos para a implementação do projeto). Os profissionais que reconheciam efeitos negativos do PJF sobre princípios das escolas públicas. Nas palavras dos autores: "financiamento público, gestão democrática, avaliação emancipatória, autonomia pedagógica do docente e esvaziamento/esmorecimento do Projeto Político e Pedagógico da escola". (RIBEIRO; GRABOWSKI; MARÇAL, 2017, p. 47).

Sobre implantação do programa criado pelo ICE no estado de São Paulo, pesquisa realizada no âmbito da gestão do programa, indicou que frente a uma rede pública profissionalizada e com um burocracia estabelecida de longa data, as proposições do ator

\footnotetext{
${ }^{21}$ A esse respeito consulta Bruno (2013), Rosar (2013), Russo (2004), entre outros.

${ }^{22}$ Tais programas, a exemplo do extinto Programa Gestão Nota 10 do Instituto Ayrton Senna
} 
privado para a gestão se limitaram à disseminação de modelo gerencial já conhecido, todavia anunciado como inovação (ADRIÃO; GARCIA, 2015).

O Programa Gestão Nota 10 em escola municipal no estado de São Paulo foi objeto de estudo em pesquisa realizada em rede nacional (ADRIÃO; PERONI, 2011).Do contato com gestores em unidade de ensino após o encerramento do programa, resultaram relatos que indicam um certo nível de permanência das proposições do IAS no cotidiano da gestão: o uso dos instrumentos de registros das rotinas, como assiduidade de alunos e professores e realização de atividades em sala de aula. O Ciclo Virtuoso (PDCA) sequer é lembrado pelos profissionais. Aparentemente a alteração que de fato foi implementada na escola diz respeito a procedimentos burocráticos sem qualquer caráter de inovação. (GARCIA; ADRIÃO; ARELARO, 2012).

As três pesquisas brevemente mencionadas anunciam a possibilidade de as "reformas" produzirem consequências outras à gestão escolar que não as esperadas. Se se trata de o setor privado pretender introduzir a lógica gerencial no cotidiano da gestão, faz-se necessário compreender melhor, a partir do interior das escolas, o que de fato é produzido quando da transferência de responsabilidades sobre a gestão escolar para atores privados e seus programas. Frente à pergunta proposta para este artigo: o que a incidência de atores privados produz para gestão escolar seguem-se algumas considerações.

\section{Considerações}

Com as políticas de cunho neoliberal e a adoção da Nova Gestão Pública enquanto referência e solução para as crises do capital, os estados nacionais imprimem reformas educativas importantes privatizando o atendimento educacional, o que implica transferência de serviços, incentivo à iniciativa privada, adoção do gerencialismo e estabelecimento de "parcerias" com atores privados para que estes atuem na implementação de políticas públicas e, dentre outras possibilidades, sobre a gestão escolar. Não apenas como inspiração e fonte de referência para a formação de gestores, mas por meio de contratos e convênios por meio dos quais se estabelecem as regras, os projetos, a avaliação e os métodos de gestão no interior da escola. 
No âmbito das unidades escolares, toda a "tecnologia de gestão" propagandeada pelos atores privados com a intenção de alterar a organização do trabalho na escola, produz menos inovação e mais recuperação de padrões já históricos no campo da administração empresarial, além de intensificação do trabalho para os gestores escolares. O registro das pesquisas vai ao encontro da ideia de acirramento da burocratização, inclusive com a ampliação dos recursos tecnológicos para registros e produção de controle. De outra parte, é também passível de questionamento o quanto tais mudanças são capazes de penetrar e se perpetuar na atuação dos gestores.

O que é mais imediatamente visível na associação entre o gestor público e o setor privado, além da realização da escola como campo de negócios, considerando-se a reforma da gestão escolar, aparentemente diz respeito a naturalização da competência privada em detrimento da competência do setor público, já discutida em vários estudos. A escola pública pode ser mais um lugar para este aprendizado entre profissionais e as novas gerações de trabalhadores.

É visível, ainda, a interdição de avanços em relação ao princípio constitucional da gestão democrática, uma vez que a democracia na gestão escolar é inviável na racionalidade administrativa empresarial.

Em síntese provisória, considera-se que tais programas tendem a estreitar o "conteúdo" da escola, ou seja, a gestão e as formas de organização, reduzindo a função educativa. As proposições, todavia, confrontam-se a um modus operandi instalado que pode oferecer algum nível de resistência, conforme se observou em São Paulo

As "reformas na gestão escolar" parecem deixar mais seguramente como legado a restrição a pauta pela democratização da escolak a aceitação e naturalização do ator privado como gestor da escola pública e as premissas mercantis como justificáveis, submetendo-se a escola lógica empresarial.

Ao final destas considerações, todavia, reconhece-se necessidade de mais estudos que, a partir do trabalho realizado na escola e com ferramentas teórico-metodológicas adequadas, investiguem a realização deste mesmo trabalho durante e após a presença do ator privado na unidade escolar.

\section{REFERÊNCIAS}


ADRIÃO, T.; GARCIA, T. Subsídio Público ao Setor Privado: reflexões sobre a gestão da escola pública no Brasil. Políticas Educativas, Porto Alegre, v. 7, n. 2, p. 110-122, 2014. Disponível em: https://seer.ufrgs.br/Poled/article/view/51031/31749. Acesso em: 10 ago. 2018.

ADRIAO, T. (coord.). Mapeamento da inserção do setor privado nas redes estaduais de educação (2005-2015). Disponível em: https://www.greppe.fe.unicamp.br/ptbr/mapeamento_da_insercao_do_setor_privado_nas_redes_estaduais_de_educacao_2005_201 5. Acesso em: 18 nov. 2018.

ADRIÃO, T. Dimensões e formas da privatização da educação no brasil: caracterização a partir de mapeamento de produções nacionais e internacionais. Currículo sem Fronteiras, v. 18, n. 1, p. 8-28, jan./abr. 2018.

ADRIÃO, T. (coord.) Mapeamento das estratégias de privatização da Educação Básica no Brasil (2005-2015). Relatório de Pesquisa. 2015.

\section{ADRIÃO, T.; PERONI, V. (Orgs.). Gestão Municipal da Educação e as parcerias com o} Instituto Ayrton Senna. Goiânia/Recife: Funape/Anpae, 2013.

ADRIÃO, T.; PERONI, V. Análise das consequências de parcerias firmadas entre municípios brasileiros e a fundação Ayrton Senna para a oferta educacional. Relatório de Pesquisa, 2011.

ARRUDA, A. N. L. B.; NÓBREGA C. L. Planejamento educacional e "modernização" da gestão educacional em Pernambuco: alguns apontamentos. RBPAE, v. 29, n. 32, p. 525-536, set/dez. 2013

BALDUINO, M. A. C. Programa Jovem de Futuro: uma proposta do Terceiro Setor para a gestão de escolas do ensino médio na rede estadual de ensino de Mato Grosso do Sul (2012-2014). Campo Grande, 2016. Tese (Doutorado em Educação) - Universidade Católica Dom Bosco.

BRAVERMAN, H. Trabalho e Capital Monopolista. A degradação do Trabalho no Século XX. 3ed. Rio de Janeiro.Editora Guanabara, 1974.

BRUNO, L. Poder e administração no capitalismo contemporâneo. In: OLIVEIRA, D. A. (org). Gestão democrática da educação: desafios contemporâneos. 10. ed. Petrópolis, RJ: Vozes, 2013.

COMERLATTO, L. P.; CAETANO, M. R. As parcerias público-privadas na educação brasileira e as decorrências na gestão da educação: o caso do Instituo Ayrton Senna (IAS). In: PERONI, V (org.) Redefinições das fronteiras entre o público e o privado: implicações para a democratização da educação. PERONI. Brasília: Liber Livro, 2013. 
GARCIA, T.; ADRIÃO, T.; BORGHI, R. A Nova Gestão Pública e o contexto brasileiro. In: MARTINS, A. M. (org.). Instituições educacionais: políticas, gestão e práticas profissionais. Santos Editora Leopoldianum, 2009. p. 13-26.

GARCIA, T.; ADRIÃO, T.; ARELARO, L. O Programa Gestão Nota 10 do Instituto Ayrton Senna na rede municipal de São José do Rio Preto: decorrências para a gestão educacional. Revista da Faculdade de Educação, Ano X, n. 18, p.123-142, jul./dez. 2012.

HILL, D. O Neoliberalismo Global, a Resistência e a Deformação da Educação. Currículo sem Fronteiras, v. 3, n. 2, p. 24-59, jul./dez. 2003.

INSTITUTO AYRTON SENNA. Formação continuada. A gestão Educacional. FOCO-IAS 3. 2011. Disponível em : http://www.redevencer.org.br/pagina/textos-para-discussao. Acesso em: 23 set. 2018

INSTITUTO AYRTON SENNA. Uma escola de Qualidade. Relatório de Resultados. 2012. Disponível em https://institutoayrtonsenna.org.br/content/dam/institutoayrtonsenna/documentos/relat\%C3\%B3riosanuais/Relatorio-Institucional-2012.pdf. Acesso em: 23 set. 2018.

INSTITUTO DE CORRESPONSABILIDADE PELA EDUCAÇÃO. Introdução às bases teóricas e metodologias do modelo escola da escolha. São Paulo. 2015 Disponível em: http://www.arcoverde.pe.gov.br/zaap/kcfinder/upload/files/pdf/processo-seletivo/apostila\%20introdu\%C3\%A7\%C3\%A3o.pdf. Acesso em: 13 mar. 2018.

INSTITUTO DE CORRESPONSABILIDADE PELA EDUCAÇÃO. Manual operacional. Modelo de Gestão - Tecnologia Empresarial Socioeducacional (TESE). Uma Nova Escola para a Juventude Brasileira Escolas de Ensino Médio em Tempo Integral. Recife, s.d. Disponível em: http://www.ccv.ufc.br/newpage/conc/seduc2010/seduc_prof/download/Manual_ModeloGesta o.pdf. Acesso em: 13 mar. 2018.

INSTITUTO DE CORRESPONSABILIDADE PELA EDUCAÇÃO. Escola da Escolha. Introdução às Bases Teóricas e Metodologias do Modelo Escola da Escolha. Recife.2015. Disponível em: http://www.arcoverde.pe.gov.br/zaap/kcfinder/upload/files/pdf/processoseletivo/apostila-\%20introdu\%C3\%A7\%C3\%A3o.pdf. Acesso em: 13 mar. 2018.

LIMA, L. C. Elementos de hiperburocratização da administração educacional. In: LUCENA, C.; REIS, J. (org.). Trabalho e Educação no século XXI. São Paulo. Editora Xamã. p.12958.

LIMA, L. Privatização lato sensu e impregnação empresarial na gestão da educação pública. Currículo sem fronteiras, v. 18, n. 1, p. 129-144, jan./abr. 2018.

MONTEIRO, M. A formação discursiva neoliberal em escolas públicas estaduais: o Projeto Jovem de Futuro do Instituto Unibanco. 2014.

MOVIMENTO BRASIL COMPETITIVO. HISTÓRICO. O início da jornada por gestão de qualidade e um país mais competitivo. Disponível em 
http://www.mbc.org.br/portal/videos/visao-brasil-2030-congresso-brasil-competitivo-2018/. Acesso em: 23 set. 2017.

OLIVEIRA, D. A.; DUARTE, M. R. T. Política e administração da educação: um estudo de algumas reformas recentes implementadas no estado de Minas Gerais. Educ. Soc.[online]. 1997.

OLIVEIRA, D. A. A Qualidade Total na Educação: os Critérios da Economia Privada na Gestão da Escola Pública. In: BRUNO, L. (Org.). Educação e Trabalho no Capitalismo Contemporâneo. São Paulo: Atlas, 1996. p. 57-90.

PARO, V. H. A educação, a política e a administração: reflexões sobre a prática do diretor de escola. Educ. Pesqui., São Paulo, v. 36, n. 3, p. 763-778, dec. 2010. Disponível em: http://www.scielo.br/scielo.php?script=sci_arttext\&pid=S1517-

97022010000300008\&lng=en\&nrm=iso. Acesso em: 6 ago. 2018.

PARO, V. H. Administração Escolar: introdução crítica. São Paulo. Cortez Editora, 2012.

PARO, V. H. Professor: artesão ou operário. São Paulo. Cortez Editora, 2018.

PERONI, V.; CAETANO, R. O público e o privado na educação Projetos em disputa?

Revista Retratos da Escola, Brasília, v. 9, n. 17, p. 337-352, jul./dez. 2015. Disponível em: http://www.esforce.org.br/. Acesso em: 28 maio 2018.

PINHEIRO, D. O programa gestão nota 10 do IAS: aproximações com a Gestão da qualidade total (GQT) e o movimento das escolas Eficazes. 2010. Disertação (Mestrado em Educação) - Universidade Estadual de Campinas - Unicamp.

RIBEIRO, J. A.; GRABOWSKI, G.; MARÇAL, F. A. Ensino Médio no Brasil - Projetos em Disputa: afinal quais os resultados da gestão por resultados? Políticas Educativas, Santa Maria, v. 10, n. 2, p. 37-50, 2017. Disponível em:

https://seer.ufrgs.br/Poled/article/view/76804/43818. Acesso em: 14 jun. 2018.

ROSAR, M. F Administração Escolar: um problema educativo ou empresarial?. 5. ed. São Paulo. Autores Associados, 2013.

RODRIGUES, P. P. Instituto Unibanco e o Projeto Jovem de Futuro: uma fora de inserção dos empresários nas políticas educacionais para o ensino Médio. 2016. Dissertação (Mestrado em Educação) - Faculdade de Filosofica, Ciências e Letras de Ribeirão Preto, Universidade de São Paulo, Ribeirão Preto, 2016.

RUSSO, M. H. Escola e Paradigmas de Gestão. EccoS: revista científica, São Paulo, v. 6, n. 1, p. 25-42, 2004.

SILVA, I. I. A atuação da Fundação Pitágoras na educação pública de Alecrim/Sp: análise sobre as implicações para gestão escolar". Campinas. Unicamp. Dissertação (Mestrado em Educação) - Universidade Estadual de Campinas, 2012. 
SOUZA, A. R.; TAVARES, T. M. A gestão educacional no Brasil: os legados da ditadura.

RBPAE, v. 30, n. 2, p. 269-285, maio/ago. 2014.

TEIXEIRA, J. J. Como os Conceitos da Gestão da Qualidade Total Podem Ser Aplicados na Prevenção da Poluição. Dissertação (Mestrado em Engenharia Mecânica) - Faculdade de Engenharia Mecânica, Universidade Estadual de Campinas, 2006.

AGRADECIMENTOS: CNPq e Fapesp pelo apoio à pesquisa citada

\section{Como referenciar este artigo}

GARCIA, TEISE. A gestão escolar no contexto da privatização na Educação Básica. Revista on line de Política e Gestão Educacional, Araraquara, v. 22, n. esp. 3, p. 1355-1376, dez., 2018. ISSN: 1519-9029. DOI: 10.22633/rpge.v22iesp3.12232

Submetido em: 10/10/2018

Aprovado em: 16/11/2018 